\title{
OGS improvements in 2012 in running the North-eastern Italy Seismic Network: the Ferrara VBB borehole seismic station
}

\author{
D. Pesaresi ${ }^{1,2}$, M. Romanelli ${ }^{1}$, C. Barnaba ${ }^{1}$, P. L. Bragato ${ }^{1}$, and G. Durì ${ }^{1}$ \\ ${ }^{1}$ OGS (Istituto Nazionale di Oceanografia e di Geofisica Sperimentale), Trieste, Italy \\ ${ }^{2}$ Istituto Nazionale di Geofisica e Vulcanologia, Roma, Italy \\ Correspondence to: D. Pesaresi (dpesaresi@inogs.it)
}

Received: 8 July 2013 - Revised: 4 June 2014 - Accepted: 13 June 2014 - Published: 22 July 2014

\begin{abstract}
The Centro di Ricerche Sismologiche (CRS, Seismological Research Centre) of the Istituto Nazionale di Oceanografia e di Geofisica Sperimentale (OGS, Italian National Institute for Oceanography and Experimental Geophysics) in Udine (Italy) after the strong earthquake of magnitude $M=6.4$ occurred in 1976 in the Italian Friuli-Venezia Giulia region, started to operate the North-eastern Italy Seismic Network: it currently consists of 17 very sensitive broad band and 18 simpler short period seismic stations, all telemetered to and acquired in real time at the OGS-CRS data centre in Udine. Real time data exchange agreements in place with other Italian, Slovenian, Austrian and Swiss seismological institutes lead to a total number of about 100 seismic stations acquired in real time, which makes the OGS the reference institute for seismic monitoring of North-eastern Italy.

The south-western edge of the OGS seismic network (Fig. 1) stands on the Po alluvial basin: earthquake localization and characterization in this area is affected by the presence of soft alluvial deposits. OGS ha already experience in running a local seismic network in high noise conditions making use of borehole installations in the case of the microseismicity monitoring of a local gas storage site for a private company. Following the $\mathrm{ML}=5.9$ earthquake that struck the Emilia region around Ferrara in Northern Italy on 20 May 2012 at 02:03:53 UTC, a cooperation of Istituto Nazionale di Geofisica e Vulcanologia, OGS, the Comune di Ferrara and the University of Ferrara lead to the reinstallation of a previously existing very broad band (VBB) borehole seismic station in Ferrara. The aim of the OGS intervention was on one hand to extend its real time seismic monitoring capabilities toward South-West, including Ferrara and its surroundings, and on the other hand to evaluate the seismic response at the site.
\end{abstract}

We will describe improvements in running the Northeastern Italy Seismic Network, including details of the Ferrara VBB borehole station configuration and installation, with first results.

\section{Introduction}

The Istituto Nazionale di Geofisica e Vulcanologia (INGV) is the Italian agency devoted to monitor in real time the seismicity on the Italian territory. Seismic events detection capabilities in Italy is variable in time and space, being very much dependant on very diverse local geological settings and noise conditions. In this case, monitoring seismicity in an alluvial basin like the Po one is a challenge, due to consistent site effects induced by soft alluvial deposits and bad coupling with the deep bedrock (Steidl et al., 1996). This problem was first tackled by INGV with an ad hoc project in 2000-2001, with the installation of a broad band seismic station nearby Ferrara in a borehole of $135 \mathrm{~m}$ depth. Comparison of recordings with a surface seismic station indicated a noise reduction of 2 decades in power spectral density at frequencies larger than $1.0 \mathrm{~Hz}$ (Cocco et al., 2001). The instrumentation in Ferrara has been working for several months but after that the seismic station was discontinued due to lack of maintenance manpower.

The Centro di Ricerche Sismologiche (CRS, Seismological Research Centre) of the Istituto Nazionale di Oceanografia e di Geofisica Sperimentale (OGS, Italian National Institute for Oceanography and Experimental Geophysics) in Udine (Italy) after the strong earthquake of magnitude $M=6.4$ occurred in 1976 in the Italian Friuli-Venezia Giulia region, started to operate the North-eastern Italy (NI) 


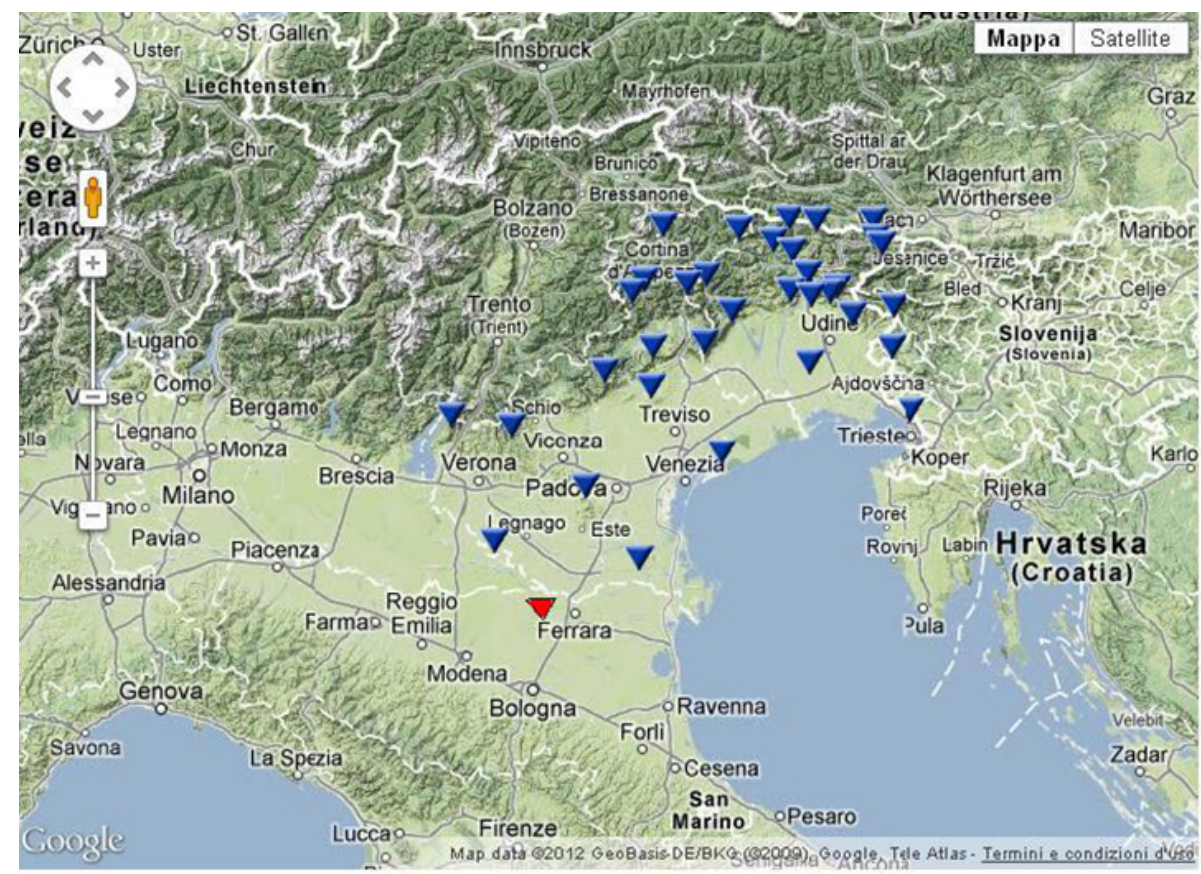

Figure 1. The North-eastern Italy Seismic Network (NI) run by OGS with the Ferrara borehole site in red.

Seismic Network: it currently consists of 17 very sensitive (Streckeisen STS-2s have $145 \mathrm{~dB}$ dynamic range) broad band and 18 simpler short period seismic stations, all telemetered to and acquired in real time at the OGS-CRS data centre in Udine (Fig. 1).

Among the various Italian institution with which OGS is cooperating for real time monitoring of local seismicity there is the Regione Veneto (Barnaba et al., 2012). The Southern part of the Veneto Region stands on the Po alluvial basin: earthquake localization and characterization is here again affected in this area by the presence of soft alluvial deposits. OGS has already experience in running a local seismic network in difficult noise conditions making use of borehole installations (Priolo et al., 2012) in the case of the monitoring of a local storage site for the EDISON company. Following the $\mathrm{ML}=5.9$ earthquake that struck the Emilia region around Ferrara in Northern Italy on 20 May 2012 at 02:03:53 UTC, a cooperation of INGV, OGS, the Comune di Ferrara and the University of Ferrara lead to the reinstallation of the very broad band borehole seismic station in Ferrara (Pesaresi et al., 2012). The aim of the OGS intervention was on one hand to extend its real time seismic monitoring capabilities toward South-West (Fig. 1), including Ferrara and its surroundings, and on the other hand to evaluate the seismic response at the site.

As concerns the superficial geology of the area where the borehole seismic station has been installed, the outcropping materials are represented by alluvial deposits of different environments, like channel and proximal levee, interfluvial, meander and swamps deposits. As a consequence, the outcropping deposits are everywhere Holocene in age substantially loose or poorly compacted in the first metersdecametres and granulometrically could vary from clay to coarse sand. Two preliminary reports prepared by the Italian Department of Civil Defence (Dipartimento Nazionale di Protezione Civile) in collaboration with other institutions describe the data recorded by the national accelerometric network and complemented by additional data recorded by a number of temporary stations (Dolce et al., 2012). These reports bear witness of strong ground motion values with an acceleration peak of about $0.9 \mathrm{~g}$ in the vertical component recorded during the $\mathrm{ML}=5.8$ earthquake of 29 May 2012 by the Mirandola station, located at about $2 \mathrm{~km}$ from the epicentre. The analysis of the seismic noise recorded at some stations shows a quite pronounced peak of the horizontal-tovertical spectral ratio $(H / V)$ in the frequency range of 0.6$0.9 \mathrm{~Hz}$ common to all stations.

\section{Installation and technical setup}

We reoccupied the borehole site in the Po alluvial basin at Casaglia village, near Ferrara town (NE Italy), $40 \mathrm{~km}$ away from the main events of 2012 Emilia seismic sequence. The site, as described in Cocco et al. (2001), is set on a structural high, and reaches the basement at $130 \mathrm{~m}$ depth. The sedimentary coverage is represented by alluvial deposits of different environment, Holocene in age; it could vary from clay to coarse sand, substantially loose or poorly compacted. The site can be classified as soft soil $\left(\mathrm{Vs}<360 \mathrm{~m} \mathrm{~s}^{-1}\right)$ according 

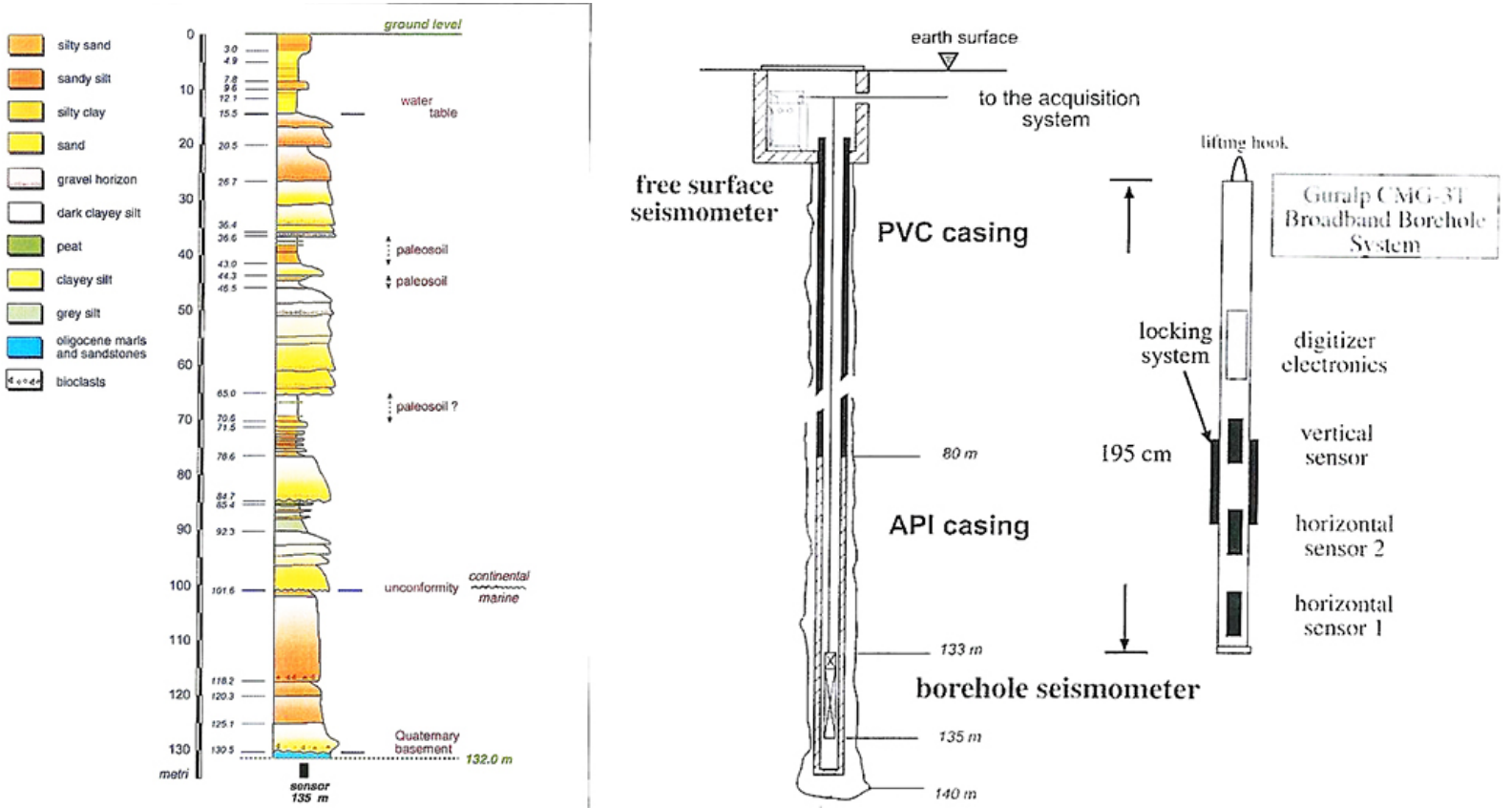

Figure 2. Stratigraphic log of the borehole site (left) and schematic of the borehole system and its installation (right) from Cocco et al. (2001).

to the cross-hole up-hole measurements (for details see Fig. 2 on the left)..

The sensors installed in the borehole is a Guralp borehole very broad band seismometer CMG-3TB with a flat response between $360 \mathrm{~s}$ and $50 \mathrm{~Hz}$ (Guralp Systems Ltd., 2006), coupled with an accelerometer Guralp CMG-5TB. The digitizer is a Guralp DM24 borehole version, with 24 bit resolution and 6 channels. Data channels are sampled at 100sps for both the seismometer and the accelerometer, and at $1 \mathrm{sps}$ for the seismometers and the state of health channels, including timing, masses positions, voltage and temperature. In Fig. 2 on the right the very broad band seismometer and the digitizer are illustrated, together with the hole-lock system to fix the all system down in the borehole.

The installation of the sensor in the borehole required some caution. First we connected the sensor with the digitizer with its data cable and its locking system. Then we connected to the digitizer $160 \mathrm{~m}$ (hole depth of $135 \mathrm{~m}$ plus some meters for cabling in conduits) of data cable and the same length of steel cable to hold the all system. We slowly lowered the all system in the borehole being careful to tight together the two cables (the data and the steel ones) every $10 \mathrm{~m}$ or so, to avoid obstruction of the hole. Once we reached the bottom of the borehole, we raised the system a little to avoid the sensor system to touch the bottom of the hole, in accordance to sensor specifications. We then fixed the sensor with its holelock system and lowered the digitizer on top of it until the digitizer own locking system held. At this point we tightened the all system at the surface. The corrected orientation of the borehole sensor has been verified later with the recordings of a teleseismic event by a surface installation at the same site managed by University of Ferrara. Some months later, OGS installed a free field station at the top of the borehole to check the quality of the broad band station. The surface free field station is a Reftek 130datalogger with a sensor Lennartz 3 -components, with an eigen period of $5 \mathrm{~s}$. Figure 3 shows the recordings at the Casaglia site at the surface and borehole sensors, for the event occurred on 12 February 2013, $M=3.8$, with an epicentral distance of $170 \mathrm{~km}$.

At the surface we installed a rack with a Guralp EAM data acquisition system running Scream software and a SeedLink server. The CMG-EAM (Embedded Acquisition Module) is a versatile module intended to integrate one or more seismic sensors with various communications systems. The unit is a Linux-based devices but no Linux knowledge is required to run it, thank to its web interface. The system is connected to the internet via a GPRS modem: the remote operation and control software is thus accessible via internet with a normal web browser. All the system features are coded with colours, with a green colour indicating normal functioning. The web interface shows also GPS coordinates of the station $\left(44.90^{\circ} \mathrm{N}\right.$ and $\left.11.54^{\circ} \mathrm{E}\right)$.

Data is recorder locally in the Guralp EAM system in files separated by component and one hour long in time. The systems has an internal hard disk of about 80 Gigabyte that is powered up only when used: this limits power consumption for better reliability. The data format chosen is the standard MiniSEED, which is a station subset of the more comprehensive Standard for the Exchange of Earthquake Data (SEED) widely internationally used format (Ahern et al., 2007). 


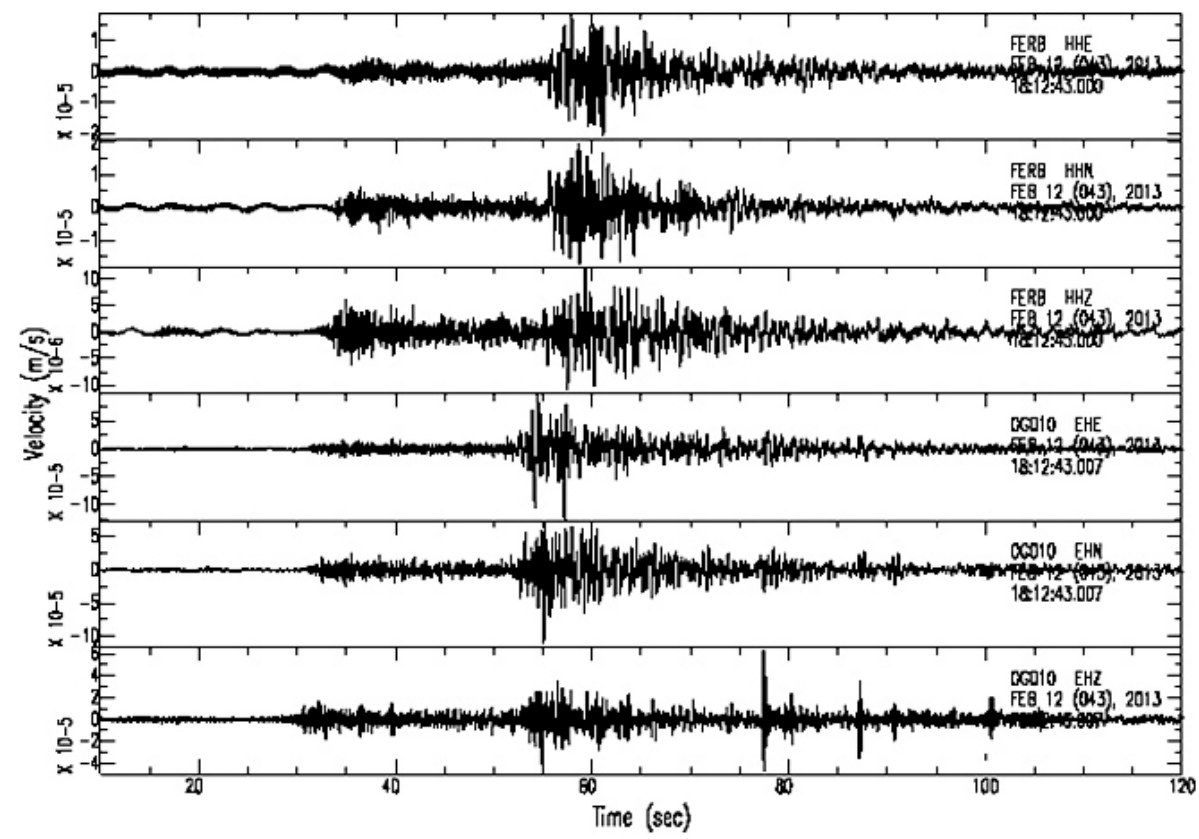

Figure 3. The event of magnitude 3.8 occurred on 12 February 2013 at 18:12:25 UTC, in the Carnian Prealps recorded by FERB VBB borehole station (top traces). For comparison, same event recorded by temporary surface station co-located (bottom traces).

The very broad band borehole seismic station of Ferrara has been already integrated in the main Antelope seismic data real time acquisition system at OGS-CRS premises in Udine, and also in the Italian National Seismic Network run by INGV in Rome. The data connection is realized through the GPRS data link by making use of the standard Antelope software module "slink2orb". This module act as a client grabbing data from the remote SeedLink server at the Ferrara borehole seismic station, feeding the data into the main Antelope server in Udine. Channel renaming was required to follow international SEED conventions (Ahern et al., 2007). Data is then forwarded from OGS premises in Udine to INGV premises in Rome through a standard SeedLink connection. Both OGS and INGV are in fact already making use of the SeisComP software to exchange seismic data in real time. The now very popular SeedLink protocol for seismic data transmission has been the core of SeisComP from the very beginning (SeisComP, 2006).

\section{First data analysis}

Background seismic noise analysis and a test of tophorizontal to bottom-horizontal spectral ratios have been conducted at the Ferrara borehole site. It is well known that although the magnitude and distance are first-order factors that control ground motion, site condition can generate significant changes in earthquake effects on buildings. Therefore, site characterization is one of the most important goals of earthquake engineering and it is an important ingredient in accurate empirical ground-motion prediction relations. However, a good quantification and understanding of the site response starts from the noise knowledge of each site. It has long been known that the reduction, quantification and understanding of seismic background noise are the first step to provide high quality data. The background noise is a limiting factor since it can mask seismic signal, especially in the low-frequency band. The importance of noise level reduction on seismic data is strongly linked to quantify the detection level of the network, that reflects directly on the completeness magnitude of an area and indirectly on the calibration of attenuation relations through regression analysis, which may be biased by non-triggering stations (McLaughlin, 1991; Bragato and Slejko, 2005).

The background noise of the Ferrara VBB borehole station has been compared with a free field station installed at the top of the borehole, to quantify the differences between the two installations. The top instrumentation installed is a Lennartz 3 -component velocimeter with a period of $5 \mathrm{~s}$ coupled with a Reftek 130 data logger.

Figure 4 compares the Power Spectral Densities (PSD) for frequencies ranging from 0.002 to $15 \mathrm{~Hz}$ and from 0.02 to $15 \mathrm{~Hz}$ for the top and the bottom, respectively. The comparison for the three components shows a clear decrease of the noise at the bottom in the whole frequency range from 0.02 to $15 \mathrm{~Hz}$, both for daytime and nighttime.

The noise level at the bottom is included within the Peterson New Model limits (Peterson, 1993), while the top location exceeds them for frequencies higher than $0.5 \mathrm{~Hz}$. The 


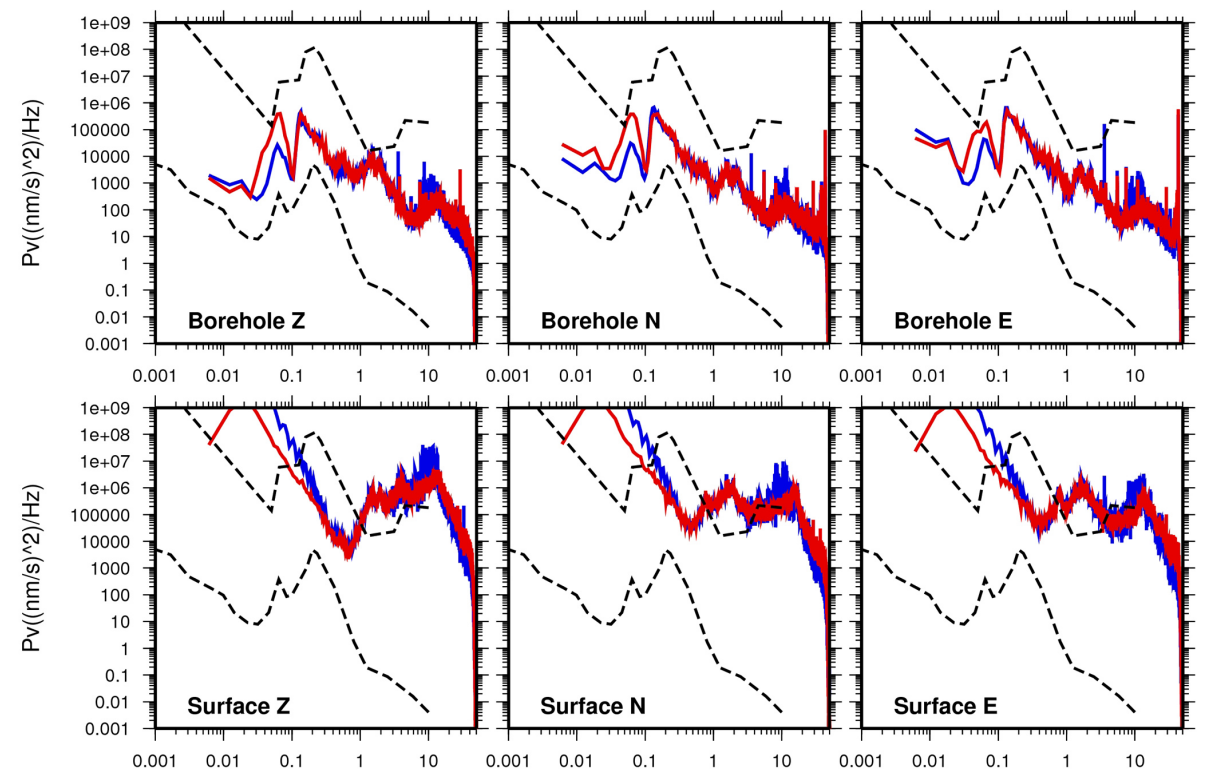

Figure 4. Power Spectral Density (PSD) of ground noise recorded at the bottom (top panels, divided by components) and at the surface (bottom panels, divided by components) compared with the Peterson New Model limits of noise (black dashed lines). Daytime (red lines) and nighttime (blue lines) are plotted for each component. Data noise are the same at top and bottom, and a reduction at the bottom site is evident.

surface site does not improve during the nighttime making the events detection quite difficult.

Preliminary site response estimations and resonance frequency have been calculated.

Site response is estimated considering the conventional spectral ratios both single-station, either by reference site of local earthquakes (see Table 1). Reference spectral ratios have been calculated considering the ratios of the mean horizontal components at the bottom borehole as a reference site, after correction of the time series to take into account the up-going and down-going wave propagation. Resonance frequencies have been detected by processing the horizontal to vertical spectral ratio of ambient noise according to Nakamura method (NHV, 1989), considering windows of data acquired at different hours of night and day, excluding possible seismic events, both local and teleseismic (Fig. 5).

Spectral ratios are calculated by two different techniques: the classical reference-site-spectral-ratio (RSSR, Borcherdt, 1970), between the surface and the bottom, after time series correction according to Bindi et al. (2010). The bottom borehole seismograms are multiplied by the factor of 2 in the time domain, for the free-surface effects, assuming vertical incidence, and then spectra are calculated and used in the ratios; the spectral ratio between the horizontals and the vertical components for selected events recorded at the surface (EHV, Lermo and Chavez-Garcia, 1994).

Considering the ambient vibration recordings with horizontal to vertical spectral ratio (NHV, Fig. 5) on $1 \mathrm{~h}$ recording window, significant peaks allow to identify the presence of underground discontinuities and frequencies of resonance.
Table 1. List of the events considered in this study.

\begin{tabular}{llllll}
\hline Date & Time UTC & Lat & Long & M & Region \\
\hline $2012-09-14$ & $02: 47: 28$ & 44.847 & 11.426 & 3.0 & Finale Emilia \\
$2012-10-03$ & $14: 41: 28$ & 44.75 & 9.63 & 4.3 & Piacenza \\
$2012-10-25$ & $23: 05: 24$ & 39.881 & 16.009 & 5.2 & Pollino \\
\hline
\end{tabular}

The surface sensor shows two clear peaks of resonance at $0.8-1$ and $1.8 \mathrm{~Hz}$, as already depicted by Cocco et al. (2001), and interpreted by Albarello and Castellaro (2011) as a stratigraphic boundary. The ratio at the bottom, as expected, is less than 2 at all the frequencies higher than $0.8 \mathrm{~Hz}$, confirming the NHV is a good proxy to local site effect estimation.

A quite similar result is obtained at the surface site when earthquakes are considered (Fig. 6): the earthquakes (EHV) horizontal to vertical spectral ratio shows amplification peaks at the same frequencies values than the ambient noise, even though the values of amplification are smaller, while the ratio between the horizontal components at top and bottom defines better the peaks in the range $1.5-3 \mathrm{~Hz}$, and the low amplification becomes sharper. It comes evident, therefor, the reference site method (RSSR) facilitate the identification of the resonance frequencies, both at low-frequency $(0.5-1 \mathrm{~Hz})$ and at higher frequencies $(1.8 \mathrm{~Hz}, 2.8 \mathrm{~Hz})$.

The results shown here are in good accordance with the observations by Cocco et al. (2001) in terms of frequencies amplified and values of amplifications, even though earthquakes recording have not been corrected by the coherence function, as suggested by Steidl et al. (1996), but by 


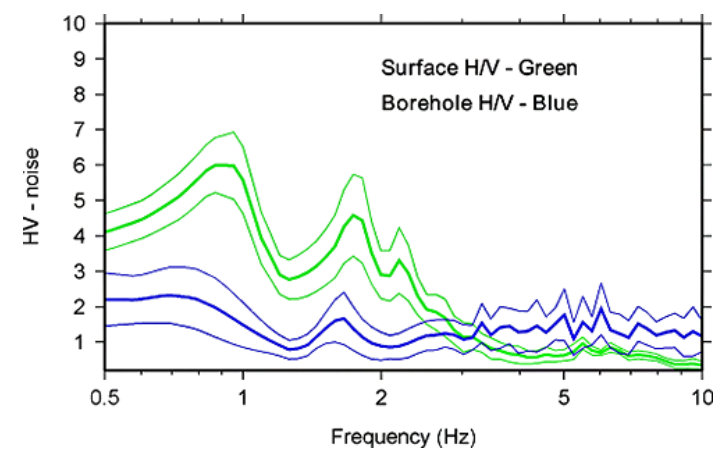

Figure 5. The horizontal to vertical spectra ratio of the ambient noise at the top (green lines) and bottom (blue lines). The amplification peak at $0.8 \mathrm{~Hz}$ at the surface is smoothed at bottom, while the peak at $1.5-2 \mathrm{~Hz}$ can be interpreted as stratigraphic boundaries.

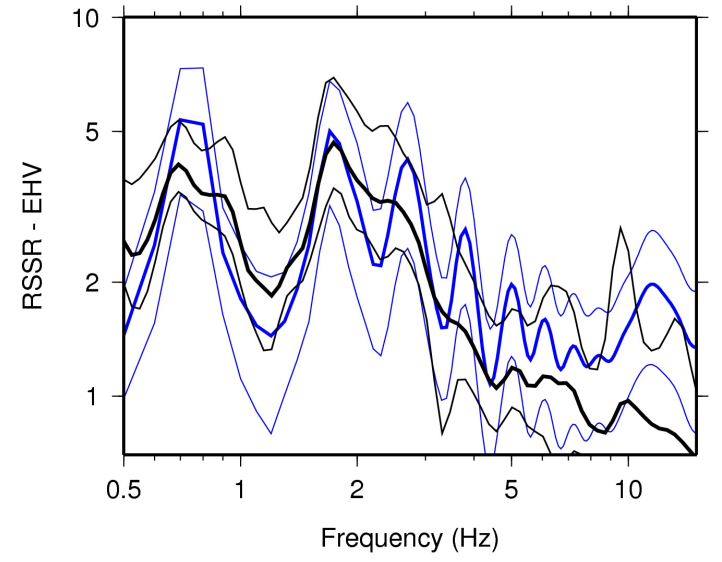

Figure 6. Comparison between the RSSR (blue lines) and EHV (black lines) methods at the Casaglia site. The RSSR is obtained dividing the surface earthquake records by the bottom borehole sensor after the path correct orientation.

multiplying by the factor of 2, for the free-surface effects, the bottom records as suggested by Bindi et al. (2010) and they confirm the stability of the site response.

\section{Conclusions}

The main 2012 OGS improvements in the North-eastern Italy Seismic Network is the reinstallation of a very broad band (VBB) borehole seismic station in Casaglia village, close to Ferrara town. The location of the Casaglia VBB borehole station is crucial to the OGS seismic network, due to extend the OGS network capabilities to monitor seismicity toward South-West, inside the Po Plain. The re-installation is the result of a cooperation between the OGS, INGV, and the Comune of Ferrara, after the seismic sequence that stuck the Emilia area in May 2012.

A surface seismic station at the top of the borehole has been install in Casaglia to compare the performances of the borehole station and to evaluate the seismic response of the deep Po Plain sedimentary basin. The preliminary analysis on the recordings show that the bottom site benefits of a clear reduction in the background noise in all the components. The surface site is extremely noisy both in daytime and nighttime, making the events detection difficult in real-time earthquake location. The fundamental resonance frequency at the surface site has been detected by the horizontal-to-vertical spectral ratio of ambient noise, while the estimation of the site amplification has been performed with the spectral ratio techniques of earthquake recordings. Surface over borehole ratios allow an easier identification of the frequency of resonance, since peaks appear sharper than those displayed by single-station methods (both $H / V$ on ambient noise and earthquakes). In particular, amplification in the range of $0.5-1 \mathrm{~Hz}, 1.8 \mathrm{~Hz}$ and $2.8 \mathrm{~Hz}$, is persistent and concordant with the results obtained by Margheriti et al. (2000) with other dataset.

The installation of a very broad band seismic station in a deep (about $130 \mathrm{~m}$ ) borehole is a delicate and expensive task (on the order of tens of thousands of euros only for the borehole): however the reduction in seismic noise and the consequent improvement in seismic event detection capabilities is the desired goal.

Acknowledgements. The authors wish to thank Lorella Dall'Olio from Comune di Ferrara for the overall project general coordination and support and for providing the site, Nasser Abu Zeid from University of Ferrara for logistic support and initial surface data, Marco Mucciarelli (OGS Centro di Ricerche Sismologiche Director) for the OGS support also financial, Michele Bertoni and Elvio Del Negro from OGS for the station installation, Antonio Rovelli, Massimo Cocco and Alessandro Amato from INGV for providing the instrumentation and the original idea. Technical works have been conducted with the financial support of the Regione Veneto in Italy, while the instrumentation installed in Ferrara is property of the INGV.

\section{References}

Ahern, T., Casey, R., Barnes, D., Benson, R., and Knight, T.: SEED Standard for the Exchange of Earthquake Data Reference Manual Format Version 2.4, http://www.fdsn.org/seed_manual/ SEEDManual_V2.4.pdf, 2007.

Albarello, D. and Castellano, S. Tecniche: Sismiche passive: indagini a stazione singola, Ingegneria Sismica, Anno 38, no. 2, 32-49, 2011

Barnaba, C., Bernardi, P., Bertoni, M., Bressan, G., Bragato, P. L., Comelli, P., Del Negro, E., Di Bartolomeo, P., Durì, G., Garbin, M., Gentili, S., Klin, P., Palmieri, F., Peruzza, L., Pesaresi, D., Petronio, L., Plasencia Linares, M. P., Ponton, C., Priolo, E., Restivo, A., Romanelli, M., Saraò, A., Snidarcig, A., Sugan, M., Urban, S., Vuan, A., and Zuliani, D.: Regione Veneto - Gestione della rete di controllo sismico, studio della sismicità regionale e ricerca sismologica a fini di protezione civile - Anno 2011, Relazione OGS n. 2012/20 CRS 7 MONET, OGS, Trieste, Italy, 2012. 
Bindi, D., Parolai, S., Picozzi, M., and Ansal, A.: Seismic input motion determined from a surface-downhole pair of sensors: a constrained deconvolution approach, Bull. Soc. Seism. Am., 100, 1375-1380, 2010.

Bonnefoy-Claudet, S., Cotton, F., and Bard, P. Y.: The nature of noise wave field and its applications for site effects studies. A literature review, Earth Sci. Rev., 79, 205-227, 2006.

Borcherdt, R. D.: Effects of local geology on ground motion near San Francisco Bay, Bull. Seismol. Soc. Am., 60, 29-61, 1970.

Bragato, P. L. and Slejko, D.: Empirical ground-motion attenuation relations for the eastern Alps in the magnitude range 2.5-6.3, BSSA, 95, 252-276, 2005.

Bragato, P. L., Di Bartolomeo, P., Pesaresi, D., Plasencia Linares, M. P., and Saraò, A.: Acquiring, archiving, analyzing and exchanging seismic data in real time at the Seismological Research Center of the OGS in Italy, Annals of Geophysics, 54, 67-75, doi:10.4401/ag-4958, 2011.

Cocco, M., Ardizzoni, F., Azzara, R. M., Dall'Olio, L., Delladio, A., Di Bona, M., Malagnini, L., Margheriti, L., and Nardi, A.: Broadband waveforms and site effects at a borehole seismometer in the Po alluvial basin (Italy), Annals of Geophysics, 44, 137154,2001

Dolce, M., Nicoletti, M., Ammirati, A., Bianconi, R., Filippi, L., Gorini, A., Marcucci, S., Palma, F., Zambonelli, E., Lavecchia, G., De Nardis, R., Brozzetti, F., Boncio, P., Cirillo, D., Romano, A., Costa, G., Gallo, A., Tiberi, L., Zoppé, G., Suhadolc, P., Ponziani, F., and Formica, A.: The Emilia Thrust Earthquake of 20 May 2012 (Northern Italy): Strong Motion And Geological Observations - Report II, National Civil Protection Department (DPC), http://www.protezionecivile.gov.it/jcms/it/ran.wp, 2012.
Guralp Systems Ltd.: CMG-3TB Operator's guide, http://www. guralp.com/documents/MAN-BHO-0001.pdf, 2006.

Lermo, J. and Chávez-García, F. J.: Are micro tremors useful in site response evaluation?, Bull. Seismol. Soc. Am., 84, 1350-1364, 1994.

Margheriti, L., Azzara, R. M., Cocco, M., Delladio, A., and Nardi, A.: Analysis of Borehole broadband recordings: Test site in the Po Basin, Northern Italy, BSSA, 90, 1454-1463, 2000.

McLaughlin, K. L.: Maximum likelihood estimation of strong motion attenuation relationships, Earthquake Spectra, 7, 267-279, 1991.

Pesaresi, D., Dall'Olio, L., Rovelli, A., Romanelli, M., Barnaba, C., and Abu Zeid, N.: Installation of a very broad band borehole seismic station in Ferrara (Emilia), Atti del $31^{\circ}$ Convegno Nazionale GNGTS, 2, 69-75, ISBN 978-88-902101-2-9, 2012.

Peterson, J.: Observations and modelling of seismic of the background seismic noise, U.S. Geol. Survey Open-file report 93 322, Albuquerque, New Mexico, 1993.

Priolo, E., Romanelli, M., Plasencia Linares, M. P., Bernardi, P., Zuliani, D., Fabris, P., Per uzza, L., and Marotta, P.: Rete di rilevamento sismico finalizzata al monitoraggio della sismicità naturale e microsismicità indotta presso la concessione di stoccaggio gas metano denominata "Collalto Stoccaggio" (TV) - Relazione conclusiva sulla realizzazione dell'infrastruttura, Relazione OGS n. 2012/4 CRS 1 MODES, OGS, Trieste, Italy, 2012.

SeisComP3, http://www.seiscomp3.org/wiki/about (last access June 2013), 2006.

Steidl, J. H., Tumarkin, A. G., and Archuleta, A. J.: What is a reference site?, BSSA, 86, 1733-1748, 1996. 